\title{
What Do We Know, What are the Current Limitations of Suspension Plasma Spraying?
}

\author{
P. Fauchais, M. Vardelle, A. Vardelle, and S. Goutier
}

(Submitted April 1, 2015; in revised form August 4, 2015)

\begin{abstract}
Nano-structured coatings should exhibit better properties than micro-structured coatings because of a high volume fraction of internal interfaces. Since the mid-nineties a large body of works have been devoted to suspension and solution plasma spraying for the deposition of finely and even nanometerstructured coatings. The aim of this paper is to take stock of our present knowledge in the field of suspension plasma spraying that is, at the moment, essentially used for oxide ceramic coatings. It will first tackle the injection of the suspension in the plasma jet and the behavior of nano or sub-micro-meter particles processed in the plasma jet core involving the liquid breakup and vaporization that releases the solid particles from the solvent droplets. It will, then, deal with the plasma torches and liquid feeding systems available to suspension spraying. It will finally discuss the key characteristics of suspensions (solvent, dispersant, and particle morphologies), designing of coating microstructure, and potential industrial applications, with the developments requested to cope with these applications.
\end{abstract}

Keywords axial injection, lamellar, particle velocity, radial injection, suspension, torch fluctuations, triplex system

\section{Introduction}

Since the nineties, much research has been devoted to the nanometer-sized features in materials and the thermal spray community has been involved in the field with works aiming to achieve coatings with sub-micro- or nano-meter sized features. The first patent on suspension plasma spraying (SPS) by University of Sherbrooke was granted in 1997 (Ref 1). The main objective of this research is to manufacture coatings with enhanced properties compared to that of conventional coatings produced with powder particles with sizes ranging between ten and one hundred micrometers. These coatings have proved to have finer grain and pore sizes and exhibit different microstructures, e.g., dense, porous. Also they can be thinner than conventional thermal spray coatings, thus bridging the gap between thermal-sprayed and vapor deposition coatings. They are produced by the piling up of molten droplets with diameters of a few tens nanometers to a few micrometers resulting in splats much smaller than those obtained in conventional spraying. Both Plasma and HVOF processes are used to spray suspensions [see the reviews (Ref 2-9)].

With so small particles two main problems had to be solved:

P. Fauchais, M. Vardelle, A. Vardelle, and S. Goutier, SPCTSUMR CNRS 7315, University of Limoges, Limoges, France. Contact e-mails: michel.vardelle@unilim.fr and pfauchais@ gmail.com.
- The injection of very small particles in the plasma spray jet as the very low inertia of particles impeded the use of gas carrier as in conventional spraying. The solution was to use either liquid carrying fine particles (suspension), or a solution of chemical precursors that, then, forms the solid particles in flight in the gas flow.

- The development of powder technologies to produce fine particles with a controlled size range. The main solutions include chemical routes to produce nanometer-sized particles or cryo-milling process to produce mainly sub-micrometer or micrometer sized particles (Ref 9). The transition from large particles to fine ones and the injection and treatment of liquid in hot gas flow have raised many questions which are not fully answered yet and this may explain why, to our best knowledge, no industrial development has been achieved to date in spite of the increased interest of industry for the applications developed in research laboratories (e.g., Methods of coating a surface and articles with coated surface, US Patent, GE, 26 June 2014, US 2014/0178641 Al). Moreover, at present, the deposition efficiency of solution or SPS is about one third of that achieved with conventional coatings and, the solid particle content of suspensions is limited to about $20 \mathrm{wt} . \%$. These both factors increase the deposition cost in comparison with conventional plasma-sprayed coatings.

This article is exclusively devoted to SPS. It does not delve into the problems linked to the experimental observation of the interaction between the liquid and plasma jet, fine particles and droplets in flight and at impact, coating formation and specific characterizations, these topics being presented in another paper of this issue. It does not present either an exhaustive reviews of the patents issued on SPS. It is restricted to discuss the main problems brought up by SPS and the potential improvements. 
The questions that will be tackled are the following:

- What happens to sub-micro- or nano-meter particles in plasma jets and how the resulting issues (low inertia, Knudsen effect and Stokes effect) can be addressed?

- Which parameters affect the interactions between the plasma jet and liquid jet or droplets (mainly fragmentation and vaporization).

- Are the current plasma torches adapted to liquid injection and treatment in plasma jets? Which plasma torches are mainly used? What are the advantages of plasma torches with liquid axial injection?

- What are the advantages and disadvantages of the current injection systems and their effect on liquid penetration into the plasma jet and further treatment (fragmentation and vaporization)? What should be the ideal injection mode?

- Which are the key characteristics of suspensions?

- Which are the parameters that control coating microstructure?

Finally, this article will conclude with the required improvements to meet the coating industry standards with suspension plasma spraying.

\section{Specific Problems Linked to Sub- micro- or Nano-meter Sized Particles Treated in Plasma Jets}

The fine particles contained in suspensions have very low mass: shifting from 10 to $0.1 \mu \mathrm{m}$ particle corresponds to a mass reduction in a ratio of $10^{-6}$. This explains why a liquid carrier, about 1000 times heavier than a gas, is used for particle injection in the plasma jet. Once the liquid under the form of drops or jet, has penetrated the plasma jet core, the drops larger than about ten micrometers are generally broken up along their trajectories and are easily accelerated. Droplets with size below about ten micrometers are rapidly evaporated releasing the solid particles they contain, which in turn are accelerated and heated. Thus, the final velocity of a particle is that of its mother droplet plus that gained once liquid is fully vaporized; its heating only occurs after the vaporization of its mother droplet.

The momentum and heat transfers between the plasma and small solid particles are rather low as their drag coefficient $C_{\mathrm{D}}$, and Nusselt number, $\mathrm{Nu}$, are reduced by the Knudsen effect. For example, Delbos et al. (Ref 10) have calculated that for a zirconia particle $0.1-\mu \mathrm{m}$ in diameter at a temperature of $1000 \mathrm{~K}$ in a plasma at $10,000 \mathrm{~K}, C_{\mathrm{D}}$ is divided by 17 and $\mathrm{Nu}$ by 11 . It means that the acceleration and heating of this particle in plasma at constant temperature and velocity are drastically delayed compared to a 5- $\mu \mathrm{m}$ particle. Moreover, under plasma spray conditions, as soon as the plasma jet expands in the surrounding atmosphere its velocities and temperatures decrease rather fast with the distance from the nozzle exit
(Ref 10). Thus, the delays in the acceleration and heating of $0.1-\mu \mathrm{m}$ particle result in particle lower velocities and temperatures. The same authors have calculated the inflight parameters of zirconia particles 5 and $0.1 \mu \mathrm{m}$ in diameter injected in $\mathrm{Ar}-\mathrm{H}_{2}$ (25 vol.\%) plasma jet with trajectories starting at a radial distance of $2 \mathrm{~mm}$ from the jet axis and $15 \mathrm{~mm}$ from the nozzle exit. Calculations were performed for a 6-mm nozzle internal diameter and a net power of $32 \mathrm{~kW}$ supplied to the gas. On the torch axis $10 \mathrm{~mm}$ farther downstream of the injection, the velocity of the 5 and $0.1 \mu \mathrm{m}$ particles were 450 and $160 \mathrm{~m} / \mathrm{s}$, respectively, and their temperature 4500 and $3000 \mathrm{~K}$, respectively. It is worth pointing out that the Knudsen effect is negligible for particles $0.1 \mu \mathrm{m}$ in diameter treated in HVOF flames.

Another problem with small particles is that they can follow the gas flow streamlines developing parallel to the surface of the substrate, and thus do not impact on it or impact laterally on peaks formed on the roughened surface (Ref 11). This is the case when their velocity and diameter close to the substrate are such that the Stokes number St is given below in Eq 1:

$\mathrm{St}=\frac{\rho_{\mathrm{p}} d_{\mathrm{p}}^{2} v_{\mathrm{p}}}{\mu_{\mathrm{g}} l_{\mathrm{BL}}}$

where $\rho$ is the particle specific mass $\left(\mathrm{kg} / \mathrm{m}^{3}\right), d$ its diameter $(\mathrm{m}), v$ its velocity $(\mathrm{m} / \mathrm{s}), \mu$ the gas molecular viscosity (Pa s), and $l_{\mathrm{BL}}(\mathrm{m})$ the thickness of the flow boundary layer, BL, in front of the substrate; subscripts $\mathrm{p}$ and $\mathrm{g}$ refer to particle and gas, respectively. $l_{\mathrm{BL}}$, varies as the inverse of the square root of the gas velocity close to the substrate and so decreases when the spray distance decreases. For example, (Ref 10), with an $\mathrm{Ar}-\mathrm{H}_{2}$ (25 vol.\%) plasma, issuing from a stick-type cathode plasma torch, $l_{\mathrm{BL}}=0.1$ $\mathrm{mm}$ at a spray distance of $40 \mathrm{~mm}$ and an YSZ particle 60 $\mathrm{nm}$ in diameter reaches a velocity of $v_{\mathrm{p}}=300 \mathrm{~m} / \mathrm{s}$ corresponding to a Stokes number St of 1 . When St is lower than 1, porous coatings with columnar structure of cauliflower- type are produced.

Therefore, because of the Knudsen and Stokes effects, the particles of suspensions can reach sufficient velocities and temperatures to form a coating only in the plasma core, where temperatures are over about $8000 \mathrm{~K}$.

Finally, during the growth of coating from the piling up of fine particles, stacking defects, called speckles, can be observed when the ratio $\mathrm{Ra} / d_{50}>2$, where $\mathrm{Ra}$ is the mean roughness of the substrate surface and $d_{50}$ the mass median diameter of particles contained in the suspension (Ref 12). Racek (Ref 13) explained the mechanism of speckle formation thanks to substrate roughness and impacting particles splashing.

\section{Interactions Between the Plasma Jet and Liquid}

Very few plasma torches allow the axial injection of the liquid suspension in the plasma torch, (see section 4) and 
in most cases, it is injected radially to the plasma jet. The most important difference with powder spraying is that liquid drops or jets can be broken up during their penetration in the transverse gas flow. With solid particles, the optimal trajectory is obtained by adjusting the particle injection force to that imparted by the hot gas jet, which, as a first approximation, results in

$m_{50} \times \gamma_{50} \approx S_{50} \times \rho \times v^{2}$,

where $m_{50}$ is the mass-median corresponding to the lognormal distribution of the mass median diameter $d_{50}$ and $\gamma_{50}$ the corresponding acceleration, $S_{50}$ the cross-section of the $d_{50}$ particle, $\rho$ the mass density of hot gases and $\mathrm{v}$ the hot gas velocity. The problem is more complex with drops which size is continuously reduced by breakup. In this case, experiments imply that

$\rho_{1} v_{1}^{2} \gg \rho_{\mathrm{g}} v_{\mathrm{g}}^{2}$

where the index 1 corresponds to the liquid and $g$ to gas flow. In addition, arc voltage fluctuations may induce strong variations of $\rho_{\mathrm{g}} v_{\mathrm{g}}^{2}$. For example, a plasma gas mixture of $\mathrm{Ar}-\mathrm{H}_{2}$ (45-15 slm), anode-nozzle of $6 \mathrm{~mm}$, constant arc current of $500 \mathrm{~A}$, and PTF4-type plasma torch, the relative voltage fluctuations $(\Delta V / \bar{V})$ can reach 0.66 as the instant voltage ranges between $V_{\min }$ and $V_{\max }$ the maximum and minimum voltages in the restrike mode with $V_{\min }=40$ and $V_{\max }=80 \mathrm{~V}$ corresponding to a mean voltage $\bar{V}=60 \mathrm{~V}$. These voltage fluctuations bring about variation in plasma jet velocities of about $800 \mathrm{~m} / \mathrm{s}$ between the instant plasma jet with $40 \mathrm{~V}$ arc voltage and that with $80 \mathrm{~V}$; the corresponding variation of the dynamic pressure of the fluid $\Delta\left(\rho v^{2}\right)$ is about $320 \%$ (Ref 14,15$)$, and thus the liquid penetration in the plasma jet is time dependent. It should be noted that with Ar-He plasmas or Ar- $\mathrm{H}_{2}$ plasmas with a volume content of $\mathrm{H}_{2}$ less than $5 \mathrm{vol} \%$, the relative arc voltage fluctuation is much lower $(\Delta V)$ $V<0.25)$ as well as the liquid dispersion in the plasma jet.

Three major zones can be identified in a plasma jet as shown in Fig. 1 (Ref 16):

- The plasma jet core (zone 1) where the heat and momentum transfers between the plasma and feedstock are the highest,

- The plasma plume (zone 2) where the heat and momentum transfers are drastically reduced,

- The plasma fringes (zone 3) where drop fragmentation can occur but the heat transfer is not high enough to achieve the melting of the fine solid particles of suspension.

Therefore, the liquid injection must ensure that most of the injected liquid reaches zone 1 of the plasma jet with very little fragmentation in zones 3 and 2 . In order to do this the liquid must be injected as close as possible to the torch nozzle exit with the injector axis aiming at the torch axis at its exit plane. However, the liquid breakup cannot be completely avoided in zones 1 and 2; this breakup brings about poorly treated droplets and not melted

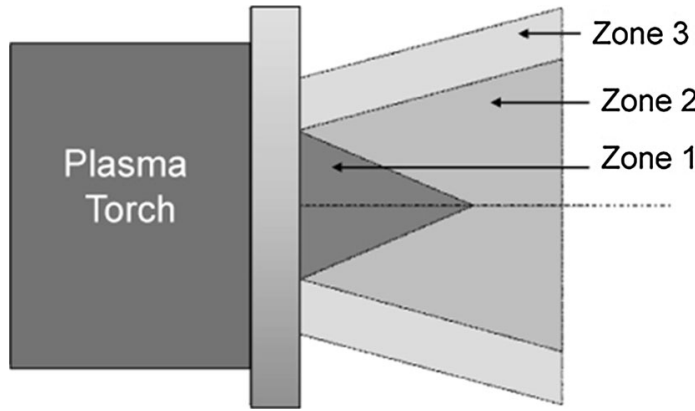

Fig. 1 Schematic of the three major zones of a stationary d.c. plasma flow (Ref 16)

particles. These particles that are sufficiently hot to stick on the substrate, form a powdery zone in the coating under construction, located around the central zone. The latter is formed by the piling up of splats resulting from the impact of droplets treated in zone 1 .

The breakup of the liquid jet into drops can be characterized by the cross flow Weber number, ratio of the force exerted by the cross flow on the liquid jet to the surface tension force:

$\mathrm{We}=\frac{\rho_{\mathrm{g}} \times u_{\mathrm{r}}^{2} \times d_{\mathrm{l}}}{\sigma_{1}}$

where $\rho_{\mathrm{g}}$ is the gas mass density $\left(\mathrm{kg} / \mathrm{m}^{3}\right), u_{\mathrm{r}}$ the relative gas-liquid velocity $(\mathrm{m} / \mathrm{s}), d_{1}$ the drop or jet diameter $(\mathrm{m})$ and $\sigma_{1}(\mathrm{~N} / \mathrm{m})$ the surface tension of the liquid. The atomization also depends, but to lesser extent, on the liquid viscosity that can be accounted for with the Ohnesorge number, Oh, when the liquid viscosity, $\mu$, is higher than $5-10 \mathrm{mPa} s$ (Ref 17). As the suspension viscosity generally ranges between a few tenths to a few tens of $\mathrm{mPa} \mathrm{s}$, Oh will not be considered in the following.

The breakup of the liquid occurs when We >12-14; over these values different breakup regimes can be observed:

- We <100: bag breakup regime; the drop is deformed as a bag-like structure.

$-100<\mathrm{We}<350$ : stripping regime; thin sheets are drawn from the periphery of the deforming drops.

- We > 350 catastrophic breakup regime: multistage breaking process.

The Weber number and so the breakup regime is partly controlled by (i) the liquid injection velocity that modifies the relative velocity between the plasma and liquid jet, $u_{\mathrm{r}}$, (ii) the initial diameter of drops or liquid jet, depending on the injector, and (iii) the suspension surface tension, $\sigma_{1}$, that mainly depends on the solvent used to prepare it. For example, at $20{ }^{\circ} \mathrm{C}$ the surface tension of water is $\sigma_{1}=71.97 \times 10^{-3} \mathrm{mN} / \mathrm{m}$ against $22.27 \times 10^{-3} \mathrm{mN} / \mathrm{m}$ for ethanol. The influence of both solvents is illustrated in Fig. 2 showing (Ref 18 ) the penetration of pure water and ethanol jets in an Ar-He plasma jet; the corresponding Weber number was 170 and 563, respectively, and the fragmentation of the water jet was delayed compared to 
(a)

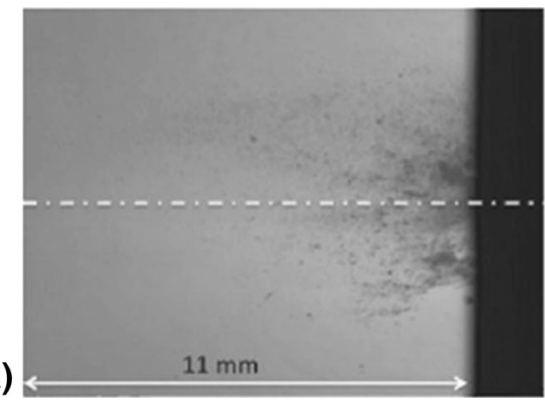

(b)

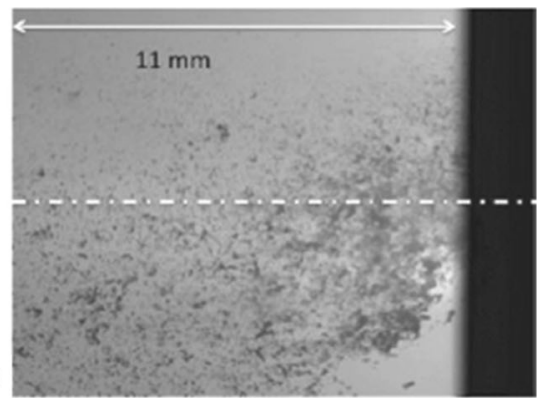

Fig. 2 Penetration of a liquid jet injected into Ar-He (40-20 slm) dc plasma jet issuing from a PTF4-type torch (enthalpy: 14 MJ/kg): (a) pure ethanol (mean We $=563)$ and $(b)$ pure water $($ mean We $=170)$ (Ref 18)

that of ethanol. It should be noted that the Weber numbers were calculated for a uniform plasma jet with no radial gradients and liquid was injected downstream of the torch nozzle exit, thus the first $2 \mathrm{~mm}$ of the interaction between the plasma and liquid were masked by the injector support. With pure ethanol (Fig 2a), almost no drops over $5 \mu \mathrm{m}$ (detection limit of the shadowgraph system) could be seen $9 \mathrm{~mm}$ downstream of the torch nozzle exit, while with water many drops over $5 \mu \mathrm{m}$ could still be observed $13 \mathrm{~mm}$ downstream of the nozzle exit. Therefore, with water-based suspension the velocity gained by solid particles from their mother droplet will be much higher than that obtained with ethanol suspension.

When the suspension penetrates the plasma jet, it undergoes both fragmentation and evaporation and the characteristic times of both mechanisms must be considered. Simple calculations based on forces and heat transfers acting on drops and droplets (Ref 14) have shown that, for drops bigger than $10 \mu \mathrm{m}$, the fragmentation time is 2 to 3 orders of magnitude shorter than that of vaporization. Once drops are fragmented into droplets of a few micrometers, the vaporization process becomes more intense. It affects the acceleration and so velocity of droplets and, thus, of particles. For example, when using an ethanol-based suspension (fast evaporation, see Fig. 2a) with YSZ particles $0.7 \mu \mathrm{m}$ in diameter, the maximum particle velocity, measured $30 \mathrm{~mm}$ downstream of the nozzle exit, was about $300 \mathrm{~m} / \mathrm{s}$ and then decreased to $230 \mathrm{~m} / \mathrm{s}$ during the $10 \mathrm{~mm}$ left to reach the substrate. Correspondingly the droplet maximum velocity, $100 \mathrm{~m} / \mathrm{s}$, was measured at $10 \mathrm{~mm}$ downstream of the nozzle exit; droplets did not exist anymore at $15 \mathrm{~mm}$. With water-based suspension droplets still existed $30 \mathrm{~mm}$ downstream of the torch exit and they achieved velocities of about $250 \mathrm{~m} / \mathrm{s}$. However, thanks to the high velocity of mother droplets, in the $10 \mathrm{~mm}$ left in the hot core of the plasma jet for the trajectory of solid particles contained in the droplets, the impact velocity of the latter on the substrate was sufficient to overcome the Stokes effect but their heating in this 10$\mathrm{mm}$ long trajectory was far to be sufficient for full melting, thus resulting in more porous coatings (Ref 8).

Liquid vaporization cooled down the plasma jet according to its vaporization energy $(2260 \mathrm{~kJ} / \mathrm{kg}$ for water and $841 \mathrm{~kJ} / \mathrm{kg}$ for ethanol). Moreover, as the suspensions with both solvents were injected with the same flow rate the enthalpy consumed with water was higher than that used for ethanol, which weight per liter is smaller $\left(0.789 \mathrm{~g} / \mathrm{cm}^{3}\right)$. With the water-based suspension the plasma jet was almost cut into two parts and recovered its symmetry $15 \mathrm{~mm}$ downstream as illustrated in Fig. 3. At a distance of $15 \mathrm{~mm}$ the jet temperature dropped of about $1500-2000 \mathrm{~K}$ and the length of its core decreased of about $10 \mathrm{~mm}$.

The combustion of ethanol occurred below $3000 \mathrm{~K}$ i.e., in the plume of the plasma jet, and so was of no help for the treatment of droplets and particles. However, the mixing of these vapors with the plasma gas and their heating up to the plasma temperature improved the heat transfer capacity of the "new" plasma formed at about 10 to $15 \mathrm{~mm}$ downstream of the nozzle exit (Ref 19).

Finally, the use of fine particles forces, with conventional stick-type cathode plasma torches, to have substrates located at $35-50 \mathrm{~mm}$ of the nozzle exit in order to have particles with a high enough inertia so that they continue along their trajectory and impact on the substrate. However, at these distances, the plasma heat flux can be over 10-25 MW/m² (Ref 12). Moreover, spraying at such short distances makes the spray pattern rather complex and hinders spraying on small turbine blades, for example.

If the above considerations are over-simplified, they give a summary of the interactions between plasma jet and suspension of nano-particles. Numerical simulations are now being developed up to now mostly based on fluid mechanics equations; they make it possible to understand the first moments of these interactions when the suspension comes into contact with the plasma jet (Ref 20,21). The predictions demonstrated the different trajectories of the drops and, consequently, different modes of breakup. However, such calculations have to involve the full physics of the process to give reliable information on mechanisms that cannot be experimentally observed.

\section{Plasma Torches and Suspensions}

\subsection{Radial Injection}

The plasma torches with stick-type cathodes, working in the $40-60 \mathrm{~kW}$ power range are still the most used in 


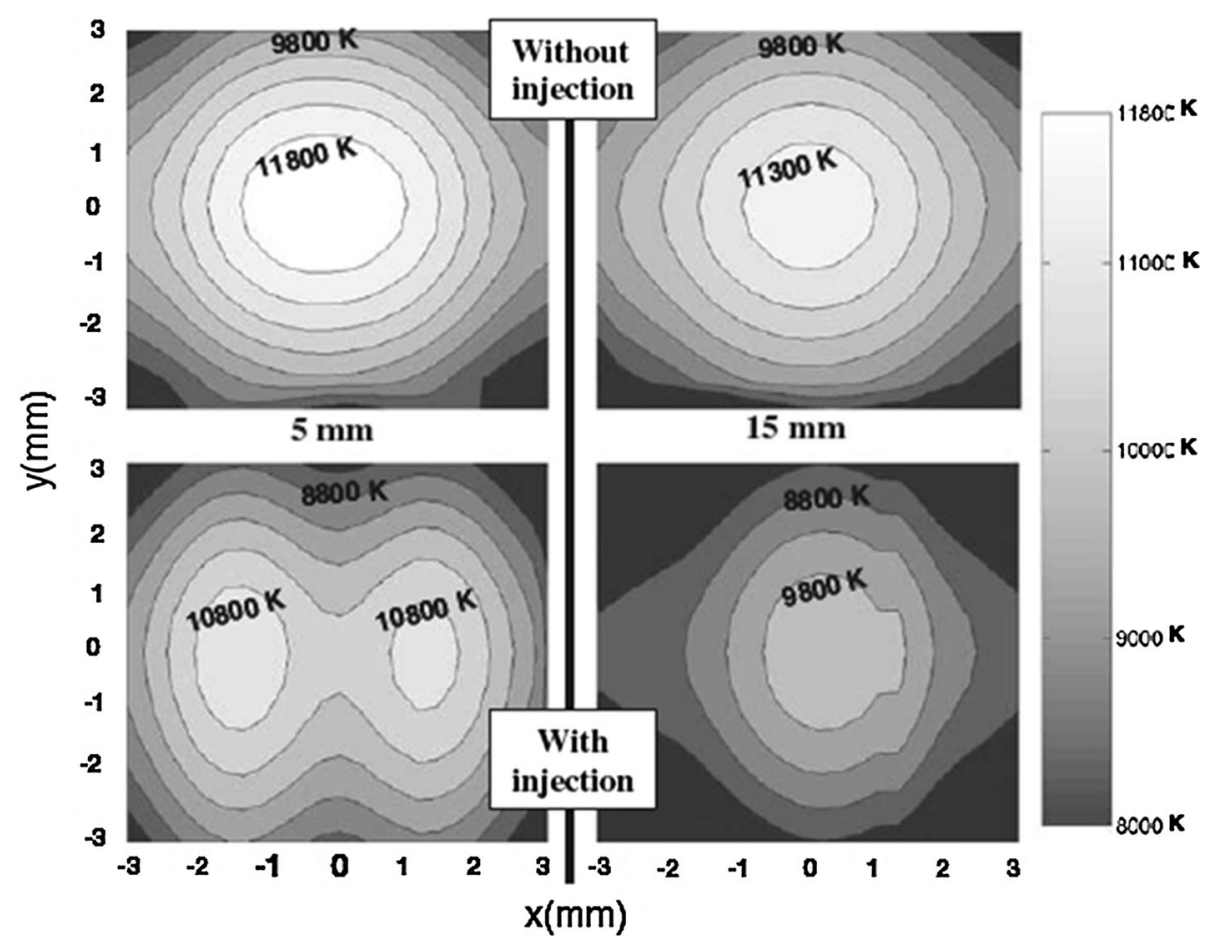

Fig. 3 Spectroscopic measurements of plasma temperature 5 and $15 \mathrm{~mm}$ downstream of anode-nozzle exit without and with water injection $(22 \mathrm{~mL} / \mathrm{min})$; Ar- $\mathrm{H}_{2}$ plasma jet with a specific enthalpy of $14.6 \mathrm{MJ} / \mathrm{kg}$ issuing from a PTF4-type plasma torch; anode-nozzle i.d. $6 \mathrm{~mm}$. (Ref 15)

conventional plasma spraying. They produce plasma jet with a core length of about $40-50 \mathrm{~mm}$. They do not seem the best adapted to suspension spraying. The previous remarks about the interactions between plasma jet and suspension (see section 3 ) suggest that the plasma jet core should be longer to improve the acceleration and heating of particles. This implies higher power level, which may also permit to increase the suspension flow rate. Another issue is the generally high voltage fluctuations of these plasma torches, which necessitates using plasma gas mixtures of $\mathrm{Ar}-\mathrm{He}$ or $\mathrm{Ar}-\mathrm{H}_{2}$ with a low $\mathrm{H}_{2}$ content ( $<5$ vol.\%) to limit arc fluctuation (Ref 22).

Another plasma torch type, which is becoming rather popular to spray suspensions [see, for example, (Ref 23)], is the Triplex torch (of Sulzer-Metco now Oerlikon-Metco). It involves three cathodes supplied by three independent electric sources resulting in three arcs attaching at a single anode. Insulating rings between the cathode and the anode-ring permits the generation of longer electric arcs, and thus higher arc voltage. When observing the plasma jet for small anode-nozzle diameters, it can be seen that they are constituted of three lobes. Thus, particles or liquid can be injected either into the lobes or between the lobes, the latter injection being called "cage effect" and resulting in the most efficient particle heating. Compared to conventional plasma torches, mean arc voltages up to 100-120 V are possible with Ar-He plasma gas mixture, instead of less than $40 \mathrm{~V}$ with conventional plasma torches. Thus, if $\Delta V$ is still about $10 \mathrm{~V}$, the relative arc voltage $\Delta V / V$ is below 0.1. Plasma jet core (zone of the jet where temperature is over $8000 \mathrm{~K}$ ) length up to $55-60 \mathrm{~mm}$ can be achieved and measurements performed with ethanol suspensions of YSZ $0.7 \mu \mathrm{m}$ in diameter showed that particle velocities can reach $500 \mathrm{~m} / \mathrm{s}$ at $30 \mathrm{~mm}$ from the nozzle exit.

Based also on the principle of cascaded arcs, two plasma torches showed up recently:

- The first one is the 10HE High Enthalpy plasma torch (Ref 24). Power levels can vary from 60 to $100 \mathrm{~kW}$ with plasma gas mixtures of $\mathrm{Ar}-\mathrm{N}_{2}-\mathrm{H}_{2}$; e.g., $79.5 \mathrm{~kW}$ with arc current of $370 \mathrm{~A}$ and voltage of $215 \mathrm{~V}$. The use of helium instead of hydrogen permits increasing plasma velocities. This torch has been used to spray suspensions of YSZ. The thermal conductivity of coatings was in a similar range as that of conventional porous APS coatings, but their thermo-cyclic fatigue lifetime was longer than that of conventional strain-tolerant coatings (Ref 25).

- The second one, produced by Oerlikon-Metco is derived from the Triplex but with a unique cathode and cascaded arc with a maximum power of $60 \mathrm{~kW}$. To the best of our knowledge, it has not yet been tested for suspension spraying.

\subsection{Axial Injection}

The axial injection of the suspension can be achieved either with direct current (DC) of radio frequency (RF) plasma torches. 
The DC plasma torch with the highest electric power (up to $120 \mathrm{~kW}$ ) for APS operated with feedstock axial injection uses three plasma torches supplied by three independent power supplies (plasma torch Axial III from Mettech Northwest corp.). The feedstock is injected axially between the three plasma jets converging within an interchangeable water-cooled nozzle followed by an extension (Ref 8, 26). With YSZ suspensions of nanometric and micrometric particles, ensemble velocities between 592 and $840 \mathrm{~m} / \mathrm{s}$ were measured with particle temperatures over the YSZ melting temperature (Ref 26). A patent was granted to Oberste-Berghaus et al. in 2006 on the method and apparatus for feeding the suspension in such a plasma torch (Ref 27). However, clogging problems might occur more frequently than with radial injection.

Aero plasma Corp., Japan, has developed a twin-cathode type plasma spray gun. It works with three plasma torches: a P-torch" with a reversed polarity (i.e., cathodic nozzle and anodic electrode), and a pair of "N-torches" with a normal polarity. The electric power is supplied between the anode of the P-torch and two cathodes of the N-torches, and the plasma jet is maintained between $\mathrm{P}$ - and $\mathrm{N}$-torches. The arc is long enough to result in high voltage with pure Argon. As the anode of $\mathrm{P}$-torch is a hollow electrode, the axial feeding of suspension is possible ( Ref 28).

RF torches have internal diameters about 5-7 times larger than those of the anode-nozzles of DC torches, and thus gas velocities are lower, proportionally in the reverse of the square of diameter ratio. Therefore, the Weber number of the liquid is lower than 10 and the injected drops cannot be fragmented; they can only be dried or vaporized. When a suspension of fine particles with or without precursor components is fed by atomization to a RF plasma torch; the suspension drops are dried and melted with or without chemical reaction. They can be either collected as a powder or sprayed onto a substrate (Ref 29-31). For suspensions made of particles hardly agglomerating solid particles are melted separately before impacting the substrate where they form splats with diameters in the few micrometer range or below while for fine particles agglomerating easily, such as those prepared by chemical routes, the solid particles sinter and then melt forming droplets in the tens of micrometer-size range

\section{Injectors for Liquid Feedstock}

An ideal injector to feed the suspension in the plasma jet should ensure an independent control of velocities and diameters of drops or liquid jet; also with atomizers, the spatial dispersion of droplets relatively to the injector axis should be narrow. It is worthy to note that as liquid is incompressible its velocity determines its flow rate.

The current methods used to inject the liquid suspension in the plasma jet encompass atomization and mechanical injection. In spray atomization (Ref 32) a low velocity liquid jet is injected inside a nozzle where a gas (mostly argon because of its high mass) fragments it, according to Weber number, before its expansion within the body of the nozzle. Atomization is affected by the gasto-liquid mass ratio, nozzle design, and properties of the liquid (density, surface tension, dynamic viscosity). The droplet velocities and sizes are controlled but not independently by the liquid pressure, atomizing gas mass flow rate and pressure (Ref 33, 34). A few patents have been issued on this topic [e.g., (Ref 35-37)], the involvement of companies such as Praxair and Oerlikon-Metco, pointing out their interest for the process.

At the end of the nineties, Blazdell and Kuroda were the firsts to use a continuous ink jet printer to inject suspensions radially in a plasma jet (Ref 38). In mechanical injection the liquid is contained in a pressurized reservoir from where it is forced through a nozzle of given internal diameter, i.d. (Ref 10). The limiting parameters are related to the nozzle i.d.: when it is too small it promotes clogging and requires a high pressure to keep the same liquid flow rate for different nozzle i.ds. For example, with a nozzle i.d. of $150 \mu \mathrm{m}$, corresponding roughly to a liquid jet of $300 \mu \mathrm{m}$ in diameter, the injection velocities compatible with Eq (3) were achieved with pressures below $10 \mathrm{MPa}$. If the injector i.d. was decreased to $50 \mu \mathrm{m}$, the same liquid flow rate was achieved when 81 multiplied the pressure of the liquid in the reservoir. Another injection method consists in adding to the previous set-up a magnetostrictive rod at the backside of the nozzle, which superimposes pressure pulses at variable frequencies (up to a few tens of $\mathrm{kHz}$ ). However, the theoretical diameter, $d_{1}$, of drops is a function of the liquid flow velocity, and therefore these two parameters cannot be controlled separately.

To conclude the ideal injector is still to be invented.

\section{Influence of Suspension Characteristics}

The main parameters characterizing a suspension are linked both to the properties of the solid particles and those of the suspension as presented in Fig 4 from Pot-

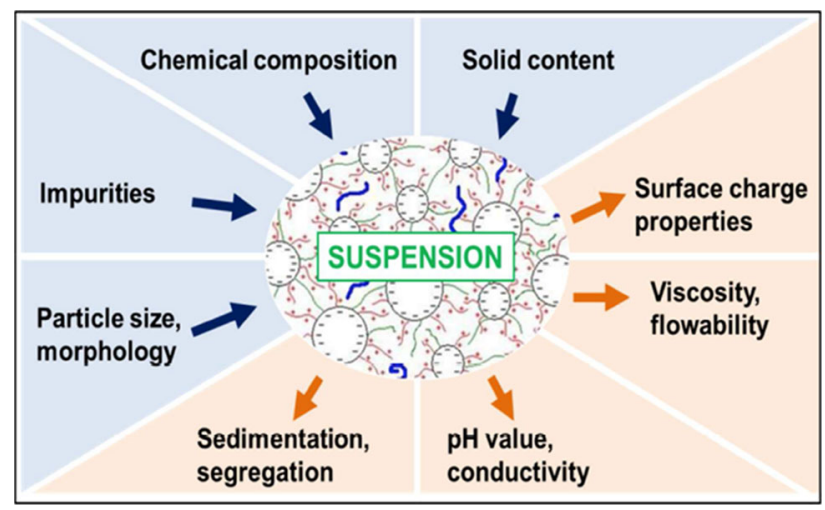

Fig. 4 Suspension parameters: initial parameters defined by the solid particles (Solid content, Chemical composition, Impurities, Particle size, morphology) and those resulting from suspension (Sedimentation, segregation, PH value, conductivity, Viscosity, flowability, Surface charge properties) (Ref 39) 
thoff and Toma (Ref 39). An ideal suspension should have the following characteristics (Ref 39):

- Good flow ability and thus low viscosity,

- Good stability with no sedimentation, especially during the spray process. For that electrostatic, steric, or electro steric repulsions are used as dispersion mechanisms with also combinations of them. The native $\mathrm{pH}$ value of the suspension, which may be affected by the solid content and dispersant, participates to the particle surface charge and is an important property,

- Use of particles which morphologies, depending on manufacturing process, do not result in their aggregation or agglomeration, and also with low level of impurities,

- Mechanical mixing during the spray process can also help keeping the particles suspended,

- Solid content higher than 60 wt. \% with high deposition efficiency. However, at present coatings made with suspensions with a solid content of over $15-20$ wt. $\%$ exhibit poor thermo-mechanical properties. Increasing the quantity of powder sprayed by suspension requires significantly greater amounts of plasma energy to fully treat the feedstock suspensions. It can be achieved, for example, using Axial III or $100 \mathrm{HE}$ cascaded arc type plasma torches. Beside the power level, the nature and quantity of dispersant must be adapted to reduce the suspension viscosity, which can be multiplied by 5 when shifting from 5 vol.\% of solid to 20 vol.\% (Ref 40). When considering YSZ particles in aqueous suspension, 20 vol. \% corresponds to 59.6 wt. \%.

- Use of water solvent preferentially to organic solvents to avoid the formation of undesirable carbon particles in coatings and also to limit risk (inflammation, explosion...) and lower the process operation cost, but here again high power plasma is required,

- No corrosive components,

- Good reproducibility between batches.

The possible problems will be illustrated through a few examples. The acid-base properties of particles depend mainly on the oxide layer present at their surfaces and it is the reason why it is difficult to associate different particles. A typical example is that of the suspension of WC-Co (Ref 41): $\mathrm{WO}_{3}$ is a Lewis acid while $\mathrm{CoO}$ is basic, making the system difficult to disperse. Oberste Berghaus et al. (Ref 41) have used polyethyleneimine, cationic polyelectrolyte adsorbed onto the $\mathrm{WO}_{3}$ particle surfaces that can be charged positively by protonation of the amine groups, i.e., by adjusting the $\mathrm{pH}$ to less basic conditions. However, care had to be taken when adding acid to increase the $\mathrm{pH}$, too high $\mathrm{pH}$ dissolving Co. This probably explains why particles in suspension spraying are up to now mainly oxides.

The different parameters linked to the suspension, and on which depend the quality of resulting coatings are the solvent, type and amount of dispersant, which increase improves the particle dispersion in the suspension and reduces the suspension viscosity, the viscosity, which for a solvent, can be increased by the addition of plasticizers with a low variation of surface tension (Ref 40, 42-45). These parameters also modify the suspension atomization.

Suspension particles also have a very important role. Their propensity to agglomerate or aggregate, depending on their morphology conditioned by their manufacturing process, plays an important role in the results. For example, Delbos et al. (Ref 10) have sprayed in the same conditions YSZ particles obtained either by attrition milling $\left(d_{50}=1.2 \mu \mathrm{m}\right.$ with a particle size distribution between 0.1 and $8 \mu \mathrm{m})$ and chemical route $\left(d_{50}=0.5 \mu \mathrm{m}\right.$ with a particle size distribution between 0.01 and $2 \mu \mathrm{m}$ ). Due to the aggregation of particles produced by chemical route, the resulting splat diameter distributions were about the same, i.e., between 0.5 and $2 \mu \mathrm{m}$. At last the purity of the powders used plays an important role. Potthoff and Toma (Ref 39) sprayed two types of $\alpha-\mathrm{Al}_{2} \mathrm{O}_{3}$ powders, the first one with $99 \%$ purity and containing sodium and the other with 99.99 purity, the coating being much better with the high purity alumina.

\section{Coatings}

\subsection{Coating Formation}

As with any coating deposition process, the substrate preparation is a key issue for the adhesion and quality of coatings. The substrate should be first preheated over the transition temperature to get rid of adsorbates and condensates (Ref 8). The molten particles impact will not result in the same types of splats than those observed in conventional plasma spraying where, depending on the impact velocity and surface tension of the molten material, the splat diameter is comprised between 3 and 6 times the initial particle diameter. With particles below one micrometer, according to the Young-Laplace equation, and very important internal pressure, the flattening degree of fully melted particles at impact on the substrate is lower than 2. In such ceramic splats, which contact surface with the substrate is relatively small (below 50 to $60 \%$ of the splat surface) and the relative thickness higher than that achieved with a flattening ratio of $4-6$, the cooling rate may be slower than that of splats obtained in conventional plasma spraying. Thus, the quenching stresses have a much lower effect and most splats have no cracks and when they have cracks, only one or two show up. The adhesion of coatings made with suspensions of fine particles is also essentially mechanical. Thus, the size of the peaks resulting from sand blasting must be adapted to the splat size. In conventional coatings the splat dimension must be 1.5 to 3 times the peak height, characterized by the Rt (Ref 8). Similar rules apply with suspensions. For example, following this rule for YSZ suspensions, coating adhesion over $50 \mathrm{MPa}$ (adhesive strength of the glue) were obtained (Ref 46). At last, probably more than in conventional spraying, defects can be created in the coating under construction by the sticking of hot particles flying in the zone 3 of plasma jet (Fig. 1) or particles ejected from zone 1 by the thermophoresis effect when they reach areas where temperature gradients are important (Ref 12). 
These insufficiently treated particles can be almost eliminated by adapted air jets, but the price for producing dense coatings is the reduction of the deposition efficiency by a ratio which can as high as 2 (Ref 18).

\subsection{Main Ceramic Coatings Studied}

Almost all types of oxide ceramic coatings have been tested in suspension plasma spraying. Several thorough reviews on these subjects in the literature, describe the different applications (Ref 3-6, 47). The most investigated and probably also those for which exist an industrial interest are the following:

- Oxides used for thermal barrier coatings (TBC) and in particular yttria stabilized zirconia (YSZ): SPS seems to be now an emerging TBC production technique, thanks to the ability of this process to generate columnar structures and replicate EB-PVD coatings (Ref 48-52). As underlined previously, the bond coat surface topography is the key issue to achieve high adhesion of the ceramic topcoat to the bond coat. Works have also been recently devoted to reduce the coating thermal conductivity by spraying rare-earth doped TBCs (Ref 53 ) or to increase the coating working temperature by spraying complex perovskites (Ref 54).

- Ceramic for medical applications: hydroxyapatite (HA) $\left.\mathrm{Ca}_{10}\left(\mathrm{PO}_{4}\right)_{6}(\mathrm{OH})_{2}\right)$ powder (Ref 55-57) or bioglass (Ref 58-60). The latter has a great potential in dental and orthopedic medical implant applications thanks to its excellent bioactivity, biocompatibility and osteo-inductivity. One patent was granted in 2010 for porous hydroxyapatite coatings (Ref 61) and another one has been submitted (Ref 62) in 2012.

- Many works have been performed to deposit using plasma suspension spraying the YSZ electrolyte (Ref 63-65) and also the anode (Ref 66, 67) and cathode (Ref 68 ) of solid oxide fuel cells (SOFCs). For the electrolyte (Ref 63, 64) dense coatings were obtained with the Axial III plasma torch.

- Alumina-zirconia composites deposited using the Axial III plasma torch were studied as potential thermal barrier coating of pseudo-eutectic composition of alumina-yttria-stabilized zirconia (Ref 69-71).

- Photocatalytic coatings of Titanium oxides were deposited. It was found that the good photo catalytic activity did not correlate with the anatase content (Ref 72) and nitrogen doping enhanced it (Ref 73).

- Other potential applications involve: wear-resistant coatings made of $\mathrm{Al}_{2} \mathrm{O}_{3}$ or $\mathrm{Al}_{2} \mathrm{O}_{3}$ and $\mathrm{YSZ}$ (Ref 74). YSZ (Ref 75) and yttria coatings, deposited with a torch with axial injection exhibited high density, uniform structure, high hardness, high plasma erosion resistance, and retention of smoother surface after plasma erosion (Ref 76).

- Suspensions made it possible to prepare alumina coatings with a high content of corundum (Ref 77). A patent has been granted for making a multilayer ceramic coating on a smooth substrate thanks to of a first nano- structured or finely structured layer deposited by SPS (Ref 78).

\section{Conclusions}

SPS allows achieving finely structured layers with a thickness varying between a few micrometers up to a few hundreds of micrometers. Coatings exhibit enhanced thermo-mechanical properties compared to conventional coatings.

The liquid injection (radially or axially, the latter being probably the best if clogging can be avoided) in the plasma jet core and its fragmentation produces mother droplets which velocity depends strongly on their fragmentation time and is important for the solid particles contained in each droplet. These droplets, when they have a few micrometers in diameter, are vaporized releasing the solid particles that are then accelerated and melted. Their impact velocity depends on their mother droplets together with their acceleration as solid particles. Their final temperatures before impact also depends on their residence time as free particles in the plasma jet core. The construction of coatings requires that they be fully melted upon impact with velocities high enough to achieve Stokes' numbers higher than one.

The processes occurring in the plasma jet depend strongly on the liquid injectors, which are far to be optimized and plasma torches, which power levels must be high enough to achieve longer plasma jet cores that those obtained with conventional plasma spray torches. Moreover, the treatment of the liquid and solid particles of the suspension depends strongly on the properties of the suspension: solvent, dispersant, $\mathrm{pH}$, particle morphologies...

Another issue, which is not yet solved, is the necessity, according to the low inertia of fine particles at impact on the substrate, to have stand-off distances corresponding to the end of the plasma jet core. It results in very high heat fluxes, up to $20 \mathrm{MW} / \mathrm{m}^{2}$, to the substrate and requires appropriate cooling systems and relative high velocity between the torch and substrate. Moreover, such short spray distances may result in spray patterns incompatible with parts having complex shapes.

At last, the solid feed rate and deposition efficiency, which are actually 2-3 times lower than in conventional plasma spraying should be increased. Also, no standards have been defined yet both for the spray process and suspension preparation. In spite of that, many potential applications have been described in the literature (Ref 4178 ) and could emerge in the short or medium term at an industrial level.

\section{References}

1. F. Gitzhofer, E. Bouyer, M. I. Boulos ,Suspension Plasma Spray, Patent US5609921A, 1997

2. F.-L. Toma, L.-M. Berger, C.C. Stahr, T. Naumann, and S. Langner, Microstructures and Functional Properties of Suspension-Sprayed $\mathrm{Al}_{2} \mathrm{O}_{3}$ and $\mathrm{TiO}_{2}$ Coatings: An Overview, Surface \& 
Coatings Technology, Surf. Coat. Technol., 2010, 202, p 4318-4328 (Journal of Thermal Spray Technology 19(1-2) (2010) 262-274)

3. R. Vaßen, H. Kaßner, G. Mauer, and D. Stöver, Suspension Plasma Spraying: Process Characteristics and Applications, J. Therm. Spray Technol., 2010, 19(1-2), p 219-225

4. A. Killinger, R. Gadow, G. Mauer, A. Guignard, R. Vaßen, and D. Stöver, Review of New Developments in Suspension and Solution Precursor Thermal Spray Processes, J. Therm. Spray Technol., 2011, 20(4), p 677-695

5. P. Fauchais, G. Montavon, R.S. Lima, and B.R. Marple, Engineering a New Class of Thermal Spray Nano-Based Microstructures from Agglomerated Nanostructured Particles, Suspensions and Solutions: An Invited Review, J Phys. D, 2011, 44, p 093001

6. P. Fauchais and A. Vardelle, Innovative and Emerging Processes in Plasma Spraying: From Micro- to Nanostructured Coatings, J. Phys. D Appl. Phys., 2011, 44, p 194011

7. P. Fauchais, A. Joulia, S. Goutier, C. Chazelas, M. Vardelle, A. Vardelle, and S. Rossignol, Suspension and Solution Plasma Spraying, J. Phys. D Appl. Phys., 2013, 46, p 224015

8. P. Fauchais, J. Heberlein, and M. Boulos, Thermal Spray Fundamentals, Springer, New York, 2014

9. A.K. Keshri and A. Agarwal, Plasma Processing of Nanomaterials for Functional Applications-A Review, Nanosci. Nanotechnol. Lett., 2012, 4, p 228-250

10. C. Delbos, J. Fazilleau, V. Rat, J.F. Coudert, P. Fauchais, and B. Pateyron, Phenomena Involved in Suspension Plasma Spraying Part 2: Zirconia Particle Treatment and Coating Formation, Plasma Chem. Plasma Process., 2006, 26, p 393-414

11. K. Van Every, M.J.M. Krane, and R.W. Trice, Parametric Study Of Suspension Plasma Spray Stabilized Zirconia, Surf. Coat. Technol., 2012, 206, p 2464-2473

12. Brousse-Pereira E., Elaboration by Thermal Spray of Finely Structured Elements of a High Temperature Electrolyser for Hydrogen Production: Processes, Structures and Characteristics, Ph.D. thesis, University of Limoges, 21 Sep 2010

13. O. Racek, The Effect of HVOF Particle-Substrate Interactions on Local Variations in the Coating Microstructure and the Corrosion Resistance, J. Therm. Spray Technol., 2010, 19(5), p 841851

14. J. Fazilleau, C. Delbos, V. Rat, J.-F. Coudert, P. Fauchais, and B. Pateyron, Phenomena Involved in Suspension Plasma Spraying Part 1: Suspension Injection and Behaviour, Plasma Chem. Plasma Proc., 2006, 26(4), p 371-391

15. R. Etchart-Salas, V. Rat, J.F. Coudert, P. Fauchais, N. Caron, K. Wittman, and S. Alexandre, Influence of Plasma Instabilities in Ceramic Suspension Plasma Spraying, J. Therm. Spray Techol., 2007, 16(5-6), p 857-865

16. M. Gell, E.H. Jordan, M. Teicholz, B.M. Cetegen, N. Padture, L. Xie, D. Chen, X. Ma, and J. Roth, Thermal Barrier Coatings Made by the Solution Precursor Plasma Spray Process, J. Therm. Spray Technol., 2008, 17(1), p 124-135

17. F.L. Toma, D. Sokolov, G. Bertrand, D. Klein, C. Coddet, and C. Meunier, Comparison of the Photocatalytic Behavior of $\mathrm{TiO}_{2}$ Coatings Elaborated by Different Thermal Spray Processes, J. Therm. Spray Technol., 2006, 15(4), p 576-581

18. P. Fauchais, A. Joulia, S. Goutier, C. Chazelas, M. Vardelle, A. Vardelle, and S. Rossignol, Suspension and Solution Plasma Spraying, J. Phys. D Appl. Phys., 2013, 46, p 224016

19. B. Pateyron, N. Calve, and L. Pawłowski, Influence of Water And Ethanol on Transport Properties of the Jets Used in Suspension Plasma Spraying, Surf. Coat. Technol., 2013, 220, p 257-260

20. E. Meillot, S. Vincent, C. Caruyer, J.P. Caltagirone, and D. Damiani, From DC Time-Dependent Thermal Plasma Generation to Suspension Plasma-Spraying Interactions, J. Ther. Spray Technol., 2009, 18(5-6), p 875-886

21. E. Meillot, D. Damiani, S. Vincent, C. Caruyer, and J.P. Caltagirone, Analysis by Modeling of Plasma Flow Interactions with Liquid Injection, Surf. Coat. Technol., 2013, 220, p 149-156

22. P. Fauchais, M. Vardelle, S. Goutier, and A. Vardelle, Key Challenges and Opportunities in Suspension and Solution Plasma Spraying, Plasma Chem. Plasma Process., 2015, 35(3), p 511-525

23. H. Kassner, R. Siegert, D. Hathiramani, R. Vassen, and D. Stoever, Application of Suspension Plasma Spraying (SPS) for
Manufacture of Ceramic Coatings, J. Therm. Spray Technol., 2008, 17(1), p 115-123

24. P. Sahoo, $100 \mathrm{HE}^{\mathrm{TM}}$ Plasma Spray System, Patent US20060099440 A1, 2006

25. N. Curry, K. Van Every, T. Snyder, and N. Markocsan, Thermal Conductivity Analysis and Lifetime Testing of Suspension PlasmaSprayed Thermal Barrier Coatings, Coatings, 2014, 4, p 630-650

26. F. Tarasi, M. Medraj, A. Dolatabadi, J. Oberste-Berghaus, and C. Moreau, Phase Formation and Transformation in Alumina/YSZ Nanocomposite Coating Deposited by Suspension Plasma Spray Process, J. Therm. Spray Technol., 2010, 19(4), p 787-795

27. Oberste-Berghaus J. et al. (2006) Method and Apparatus for Fine Particle Liquid Suspension Feed for Thermal Spray System and Coatings Formed Therefrom, Patent US20060289405 A1 and Method and System for Producing Coatings From Liquid Feedstock Using Axial Feed, Patent US 20110237421 A1, Licenced to Northwest Mettech Corp

28. M. Shahien, M. Suzuki, YSZ Coatings by a Twin Cathode Plasma Spray System, E. Meillot, Ed., 6th International Workshop on Suspension and Solution Thermal Spraying, Tours France Oct 8, 9, 2014

29. E. Bouyer, F. Gitzhofer, and M.I. Boulos, The Suspension Plasma Spraying of Bioceramics by Induction Plasma, JOM, 1997, 49, p 58-62

30. L. Jia and F. Gitzhofer, Induction Plasma Synthesis of Nanostructured SOFCs Electrolyte Using Solution and Suspension Plasma Spraying: A Comparative Study, J. Therm. Spray Technol., 2010, 19(3), p 566-574

31. Y. Shen, V.A.B. Almeida, and F. Gitzhofer, Preparation of Nano-composite GDC/LSCF Cathode Material for IT-SOFC by Induction Plasma Spraying, J. Ther. Spray Technol., 2011, 20 (1-2), p 145-153

32. A.H. Lefebvre, Atomizations and Sprays, Hemisphere Pub Corp, New York, 1989

33. P. Rampon, C. Filiatre, and G. Bertrand, Suspension Plasma Spraying of YPSZ Coatings for SOFC: Suspension Atomization and Injection, J. Therm. Spray Technol., 2008, 17(1), p 105-114

34. O. Marchand, L. Girardot, M.P. Planche, P. Bertrand, Y. Bailly, and G. Bertrand, An Insight into Suspension Plasma Spray: Injection of the Suspension and its Interaction with the Plasma Flow, J. Therm. Spray Technol., 2011, 20(6), p 1310-1320

35. X. Ma, S. Murphy, J. Roth, D. Xiao, B. M, Cetegen, Patent US20077112758, 2007

36. M. Elliot, Cotler, J. Ronald, Molz Sulzer Metco (US), Inc., Apparatus for Injecting a Liquid in an Area of a Thermal Spray Gun, Patent WO2012082902 A1, 2012

37. C.A. Petorak, D.J. Lemen, A. Feuerstein, T.F. Lewis, III, M. McCoy from Praxair, System and Method For Utilization of Shrouded Plasma Spray or Shrouded Liquid Suspension Injection in Suspension Plasma Spray Processes, Application Number 20130157040, 2013

38. P. Blazdell and S. Kuroda, Plasma spraying of submicron ceramic suspensions using a continuous ink jet printer, Surf. Coat. Technol., 2000, 123(2-3), p 239-246

39. A. Potthoff, F.-L. Toma, Suspensions-Ready for Thermal Spraying?, E. Meillot, Ed., 6th International Workshop on Suspension and Solution Thermal Spraying, Tours France, Oct 8, 9, 2014

40. D. Waldbillig and O. Kesler, The Effect of Solids and Dispersant Loadings on the Suspension Viscosities and Deposition Rates of Suspension Plasma Sprayed YSZ Coatings, Surf. Coat. Technol., 2009, 203, p 2098-2101

41. J. Oberste Berghaus, B. Marple, and C. Moreau, Suspension Plasma Spraying Nanostructured WC-12Co Coatings, J. Therm. Spray Technol., 2006, 15(4), p 676-681

42. R. Rampon, O. Marchand, C. Filiatre, and G. Bertrand, Influence of Suspension Characteristics on Coatings Microstructure Obtained by Suspension Plasma Spraying, Surf. Coat. Technol., 2008, 202, p 4337-4342

43. O. Arevalo-Quintero, D. Waldbillig, and O. Kesler, An Investigation of the Dispersion of YSZ SDC, and Mixtures of YSZ/SDC Powders in Aqueous Suspensions for Application in Suspension Plasma Spraying, Surf. Coat. Technol., 2011, 205, p 5218-5227 
44. M. Vicent, E. Sánchez, G. Mallo, and R. Moreno, Study of Colloidal Behavior and Rheology of $\mathrm{Al}_{2} \mathrm{O}_{3}-\mathrm{TiO}_{2}$ Nano-Suspensions to Obtain Free-Flowing Spray-Dried Granules for Atmospheric Plasma Spraying, Ceram. Int., 2013, 39, p 8103-8111

45. M. Marr, J. Kuhn, C. Metcalfe, J. Harris, and O. Kesler, Electrochemical Performance of Solid Oxide Fuel Cells Having Electrolytes Made by Suspension and Solution Precursor Plasma Spraying, J. Power Sources, 2014, 245, p 398-405

46. Bidron G., Physicochemical Multi-scale of Interfaces for the Understanding of the Adhesion of Plasma Sprayed Sub-micrometer Sized Powders, Ph.D. University of Limoges, Nov 14, 2014

47. H. Kassner, R. Siegert, D. Hathiramani, R. Vassen, and D. Stoever, Application of Suspension Plasma Spraying (SPS) for Manufacture of Ceramic Coatings, J. Therm. Spray Technol., 2008, 17(1), p 115-123

48. R. Vassen, H. Kassner, G. Mauer, and D. Stöver, Suspension Plasma Spraying: Process Characteristics and Applications, J. Therm. Spray Technol., 2010, 19(1-2), p 219-225

49. A. Guignard, G. Mauer, R. Vaßen, and D. Stöver, Deposition and Characteristics of Submicrometer-Structured Thermal Barrier Coatings by Suspension Plasma Spraying, J. Therm. Spray Technol., 2012, 21(3-4), p 416-424

50. L. Łatka, A. Cattini, L. Pawłowski, S. Valette, B. Pateyron, J.-P. Lecompte, R. Kumar, and A. Denoirjean, Thermal Diffusivity and Conductivity of Yttria Stabilized Zirconia Coatings Obtained by Suspension Plasma spraying, Surf. Coat. Technol., 2012, 208, p 87-91

51. Y. Zhao, D. Li, X. Zhong, H. Zhao, L. Wang, F. Shao, C. Liu, and S. Tao, Thermal shock behaviors of YSZ thick thermal barrier coatings fabricated by suspension and atmospheric plasma spraying, Surf. Coat. Technol., 2014, 249, p 48-55

52. Ganvir A. N. Markocsan, P. Nylen, Comparative Analysis of Thermal Barrier Coatings Produced Using Suspension and Solution Precursors, E. Meillot Ed.,Workshop on Suspension and Solution Thermal Spraying, Tours France Oct 8, 9, 2014

53. S. Gong, K. VanEvery, H. Wang, and R.W. Trice, Microstructure and Thermal Properties of Inflight Rare-Earth Doped Thermal Barriers Prepared by Suspension Plasma Spray, J. Eur. Ceram. Soc., 2014, 34, p 1243-1253

54. Schlegel N., D. Sebold, Y. J. Sohn, G. Mauer, R. Vaßen, Thermal Cycling Performance of a Columnar Structured Complex Perovskite in a Temperature Gradient Test, E. Meillot Ed., Workshop on Suspension and Solution Thermal Spraying, Tours France Oct 8, 9, 2014

55. L. Łatka, L. Pawlowski, D. Chicot, C. Pierlot, and F. Petit, Mechanical Properties of Suspension Plasma Sprayed Hydroxyapatite Coatings Submitted to Simulated Body Fluid, Surf. Coat. Technol., 2010, 205, p 954-960

56. T. Huang, Y. Xiao, S. Wang, Y. Huang, X. Liu, F. Wu, and Z. Gu, Nanostructured $\mathrm{Si}, \mathrm{Mg}, \mathrm{CO}_{3}{ }^{2-}$ Substituted Hydroxyapatite Coatings Deposited by Liquid Precursor Plasma Spraying: Synthesis and Characterization, J. Therm. Spray Technol., 2011, 20(4), p 829-836

57. A. Cattini, D. Bellucci, A. Sola, L. Pawłowski, and V. Cannillo, Suspension Plasma Spraying of Optimised Functionally Graded Coatings of Bioactive Glass/Hydroxyapatite, Surf. Coat. Technol., 2013, 236, p 118-126

58. Y. Xiao, L. Song, X. Liu, H. Yi, T. Huang, Y. Wu, J. Chen, and F. $\mathrm{Wu}$, Nanostructured Bioactive Glass-Ceramic Coatings Deposited by The Liquid Precursor Plasma Spraying Process, Appl. Surf. Sci., 2011, 257, p 1898-1905

59. A. Cattini, L. Łatka, D. Bellucci, G. Bolelli, A. Sola, L. Lusvarghi, L. Pawłowski, and V. Cannillo, Suspension plasma sprayed bioactive glass coatings: Effects of processing on Microstructure, Mechanical Properties and In-Vitro Behavior, Surf. Coat. Technol., 2013, 220, p 52-59

60. Z. Znamirowski, W. Posadowski, L. Pawłowski, A. Cattini, and L. Łatka, Electron Emission from the Zirconium Coated Suspension Plasma Sprayed Bioglass, Surf. Coat. Technol., 2015, 268, p 63-69
61. F. Wu et al. Method for Preparing Porous Hydroxyapatite Coatings by Suspension Plasma Spraying, Patent WO 2010130109 A1, 2010

62. Unknown, Method for Preparing Porous Hydroxyapatite Coatings by Suspension Plasma Spraying, Patent Application Number AC23C412FI, 2012

63. D. Waldbillig and O. Kesler, Electrochemical Testing of Suspension Plasma Sprayed Solid Oxide Fuel Cell Electrolytes, J. Power Sources, 2011, 196, p 5423-5431

64. A. Macwan, D.L. Chen, M. Marr, and O. Kesler, Residual Stresses in Suspension Plasma Sprayed Electrolytes in MetalSupported Solid Oxide Fuel Cell Half Cells, J. Power Sources, 2013, 221, p 397-405

65. Y. Wang, J.-G. Legoux, R. Neagu, S. Hui, and B.R. Marple, Suspension Plasma Spray and Performance Characterization of Half Cells with NiO/YSZ, J. Therm. Spray Technol., 2012, 21(1), p 7-15

66. C. Metcalfe, J. Kuhn, and O. Kesler, Characterization of Ni-YSZ Anodes for Solid Oxide Fuel Cells Fabricated by Suspension Plasma Spraying with Axial Feedstock Injection, J. Power Sources, 2013, 243, p 172-180

67. M. Cuglietta, J. Kuhn, and O. Kesler, A Novel Hybrid AxialRadial Atmospheric Plasma Spraying Technique for the Fabrication of Solid Oxide Fuel Cell Anodes Containing $\mathrm{Cu} \mathrm{Co}, \mathrm{Ni}$, and Samaria-Doped Ceria, J. Therm. Spray Technol., 2013, 22(5), p 609-621

68. X.-M. Wang, C.-X. Li, C.-J. Li, and G.-J. Yang, Effect of Microstructures on Electrochemical Behavior of $\mathrm{La}_{0.8} \mathrm{Sr}_{0.2} \mathrm{MnO}_{3}$ Deposited by Suspension Plasma Spraying, Int. J. Hydrog. Energy, 2010, 35, p 3152-3158

69. F. Tarasi, M. Medraj, A. Dolatabadi, J. Oberste-Berghaus, and C. Moreau, Phase Formation and Transformation in Alumina/YSZ Nanocomposite Coating Deposited by Suspension Plasma Spray Process, J. Therm. Spray Technol., 2010, 19(4), p 787-795

70. F. Tarasi, M. Medraj, A. Dolatabadi, J. Oberste-Berghaus, and C. Moreau, Amorphous and Crystalline Phase Formation During Suspension Plasma Spraying of The Alumina-Zirconia Composite, J. Eur. Ceram. Soc., 2011, 31, p 2903-2913

71. F. Tarasi, M. Medraj, A. Dolatabadi, J. Oberste-Berghaus, and C. Moreau, Enhancement of Amorphous Phase Formation in Alumina-YSZ Coatings Deposited by Suspension Plasma Spray Process, Surf.Coat. Technol., 2013, 220, p 191-198

72. E. Bannier, G. Darut, E. Sánchez, A. Denoirjean, M.C. Bordes, M.D. Salvador, E. Rayón, and H. Ageorges, Microstructure and Photocatalytic Activity of Suspension Plasma Sprayed $\mathrm{TiO}_{2}$ Coatings on Steel and Glass Substrates, Surf. Coat. Technol., 2011, 206, p 378-386

73. G. Mauer, A. Guignard, and R. Vaßen, Plasma Spraying of Efficient Photoactive $\mathrm{TiO}_{2}$ Coatings, Surf. Coat. Technol., 2013, 220, $\mathrm{p} 40-43$

74. O. Tingaud, P. Bertrand, and G. Bertrand, Microstructure and Tribological Behavior of Suspension Plasma Sprayed $\mathrm{Al}_{2} \mathrm{O}_{3}$ and $\mathrm{Al}_{2} \mathrm{O}_{3}$-YSZ Composite Coatings, Surf. Coat. Technol., 2010, 205, p 1004-1008

75. G. Darut, H. Ageorges, A. Denoirjean, and P. Fauchais, Tribological Performances of YSZ Composite coatings Manufactured by Suspension Plasma Spraying, Surf. Coat. Technol., 2013, 217, p $172-180$

76. J. Kitamura, Z. Tang, H. Mizuno, K. Sato, and A. Burgess, Structural, Mechanical and Erosion Properties of Yttrium Oxide Coatings by Axial Suspension Plasma Spraying for Electronics Applications, J. Therm. Spray Technol., 2011, 20(1-2), p 170-185

77. F.-L. Toma, Thermally sprayed $\mathrm{Al}_{2} \mathrm{O}_{3}$ Coatings Having a High Content of Corundum Without any Property-Reducing Additives, and Method for the Production Thereof, Patent US8318261 B2, 2012

78. E. Meillot, R. Vert, J. Toulc'Hoat, G. Mariaux, A. Vardelle, Method for Preparing a Multilayer Coating on a Substrate Surface by Means of Thermal Spraying, Patent US20130101745 A1, 2013 